
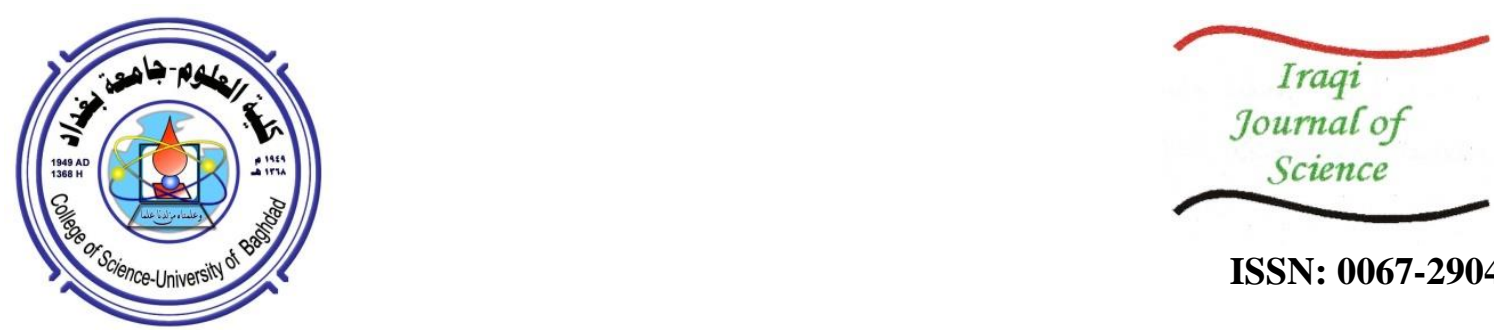

ISSN: 0067-2904

\title{
Treatment of Radioactive Liquid Waste Using Bentonite
}

\author{
Aamir Abdullah Mohammed ${ }^{1}$, Hayder S. Hussain ${ }^{1}$, Salam K. Al-Nasri ${ }^{2}$ \\ ${ }^{1}$ Physics Department, College of Science, University of Baghdad. \\ ${ }^{2}$ Ministry of Science and Technology.
}

Received: $14 / 2 / 2020$

Accepted: $10 / 6 / 2020$

\begin{abstract}
Radioactive liquid waste contaminated with cesium-137 found in the radiochemistry laboratories at Tuwaitha site, south of Baghdad, was treated in this work. Bentonite was used as a sorbent material for the removal of radioactive cesium-137 from liquid waste by ion exchange method. The results indicated that the best removal efficiency obtained was $95.13 \%$ with experimental conditions of 2 $\mathrm{h}$ mixture time, $0.04 \mathrm{~g}$ sorbent mass, and $\mathrm{pH}=10$ for the radioactive liquid. It was found that the experimental results match well with Langmuir and Freundlich models, with better matching with the latter.
\end{abstract}

Keywords: Cesium-137, Bentonite, Isotherm.
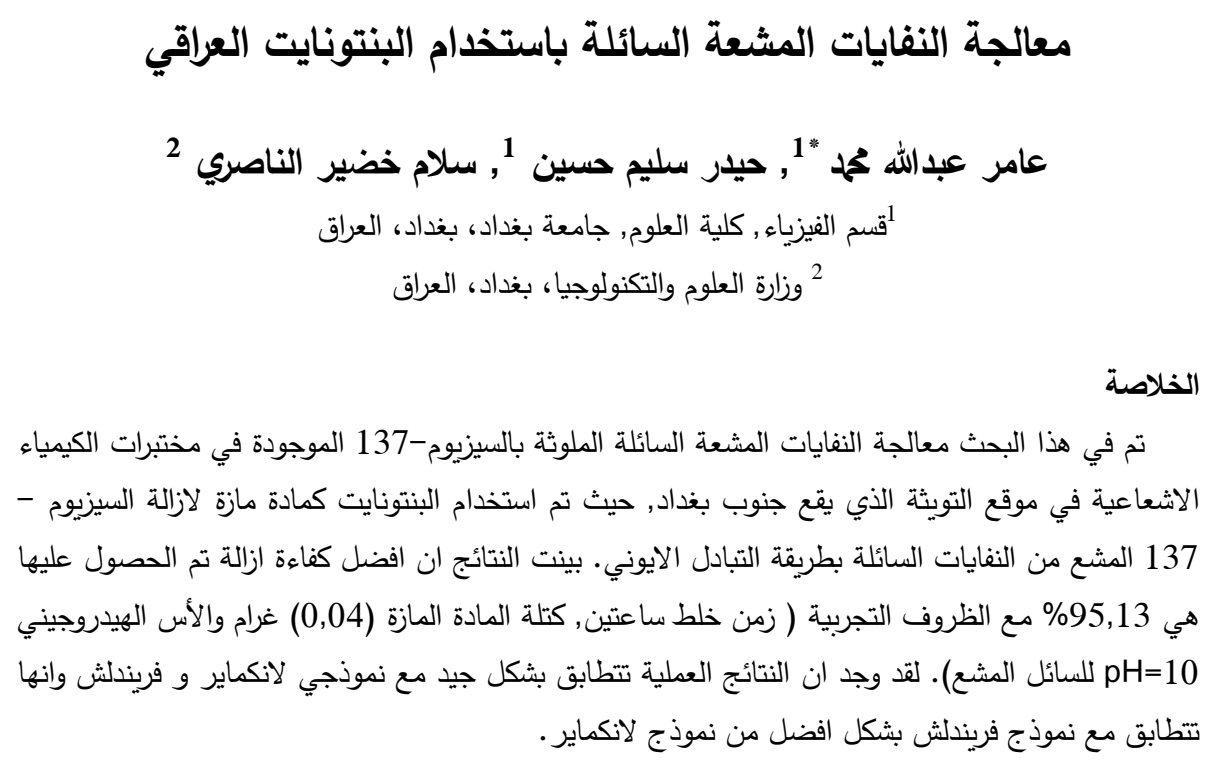

\section{1- Introduction}

Rising urbanization, growth, industrialization, and other human activities have been causing increased environmental pollution in the world [1]. These contaminants pose serious threats to human environment. As one of the most important fission radionuclides in reactors, a great attention has been always directed to cesium-137 (half - life 30 years) due to its gamma radiation. It is hazardous for human health and environment [2]. There are increased endeavors that aim at disconnecting the dissolvable radioactive contaminants from watery waste through fixing them onto solid materials that can be discarded in a repository [3,4]. Radiations can create destructive impacts on living life forms. Because of ignorance and unplanned conditions, various instances of damage, ranging from minor 
early skin injuries to delayed bone cancer and leukemia were reported among radiologists and others who were exposed to excessive amounts of radiations. When the first definitive "maximum permissible" levels of exposure to radiation were instituted, their general acceptance have led to a marked decrease in the incidence of radiation injuries [5]. Handling radioactive fluid waste includes the utilization of sundry methods such as filtration, precipitation, sorption, ion exchange, evaporation and/or membrane separation to meet the requirements, both for the release of cleaned effluents into nature and the conditioning of waste concentrates for disposal. New and improved substances and processes are under study and development in different countries [6]. Among these processes, inorganic ion exchange is a more adequate and suitable candidate for the mild or low radioactive wastewater due to its specific selectivity and radiation and thermic stabilities [7]. Smectic clays, always known as bentonites and utilized in a variety of industrial applications, are the most widely used and most interesting group of clay minerals [8]. Bentonite is described as an octahedral layer of aluminum atoms fixed through two tetrahedral layers of silicon atoms. It has a net negative electric charge because of the isomorphic exchange of $\mathrm{Al}^{3+}$ with $\mathrm{Fe}^{2+}$ and $\mathrm{Mg}^{2+}$ in the octahedral locations and $\mathrm{Si}^{4+}$ with $\mathrm{Al}^{3+}$ in the tetrahedral locations, which is balanced via the cations such as $\mathrm{Na}^{+}$and $\mathrm{Ca}^{2+}$ existing between the layers and surrounding the edges. Natural bentonite becomes alkaline, with $\mathrm{pH}$ of $8-10$, when hydrated with water. It is hydrophilic in nature as it is firmly hydrated by water. This clarifies why bentonite has a high water absorption capacity. Bentonite additionally has an extraordinary cation exchange capacity, bonding capacity, and plasticity, along with a powerful tendency to intereact with organic compounds [9]. Sulaymon et al., studied the treatment of cesiumcontaminated radioactive liquid waste. The adsorbent materials used for extracting ${ }^{137} \mathrm{Cs}$ were bentonite and modified bentonite, with removal efficiencies of $85 \%$ and $91.8 \%$, respectively [2].

The purpose of the present work is to purify the radioactive liquid waste contaminated with cesium137 using bentonite obtained from Iraqi sources. The adsorption of $\mathrm{Cs}^{+}$, in addition to the effects of some factors such as shaking time, sorbent mass, $\mathrm{pH}$, and the activity concentration, were studied in the present work.

\section{2- Materials and methods}

2.1- Sorbent: The adsorption of radioactive cesium onto Iraqi bentonite was studied. Scanning Electron Microscope (SEM, INSPECT S50) was used for surface characterization of bentonite. It can be described as a microscope that produces magnified real images of solid specimens using a high energy electron beam. It is attached with an EDX unit, which is used to obtain more precise details by concentrating on small parts of the sample (bentonite in this study) to determine their composition. The SEM micrograph of bentonite is shown in Figure-1 and its components are listed in Table-1. The results show that the main elements of bentonite are $\mathrm{O}, \mathrm{Si}, \mathrm{Ca}, \mathrm{C}$ and $\mathrm{Al}$ ), with $\mathrm{O}$ having the highest content (58.80\% of weight).

Table 1-Betonite components.

$\begin{array}{cc}\text { Element } & \text { Weight } \% \\ \mathrm{O} & 58.80 \\ \mathrm{Si} & 14.08 \\ \mathrm{Ca} & 7.43 \\ \mathrm{C} & 7.14 \\ \mathrm{Al} & 4.56 \\ \mathrm{~S} & 2.48 \\ \mathrm{Fe} & 2.32 \\ \mathrm{Mg} & 1.72 \\ \mathrm{Na} & 1.10 \\ \mathrm{P} & 0.20 \\ \mathrm{Cl} & 0.17\end{array}$




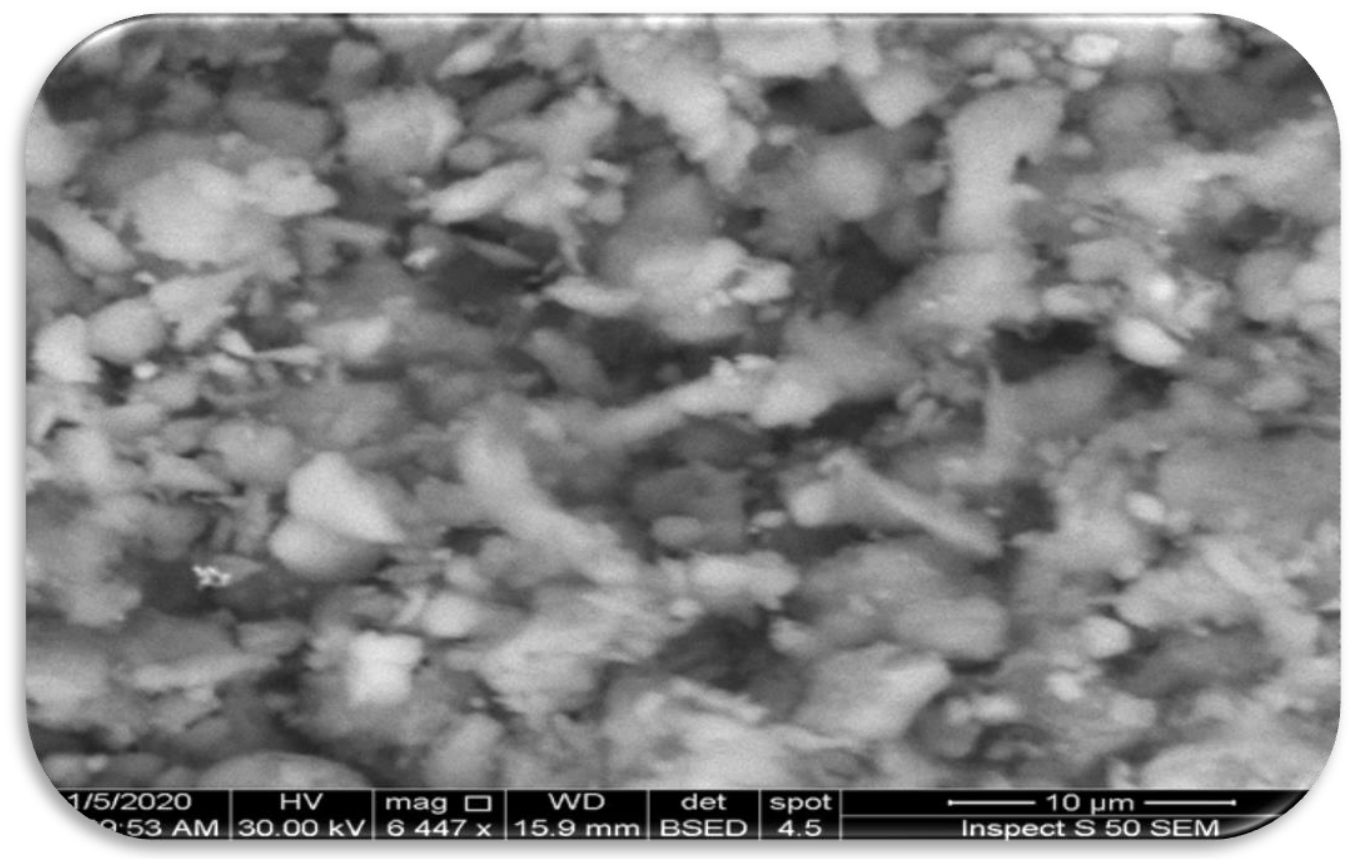

Figure 1-SEM for bentonite (scale $10 \mu \mathrm{m}$ ).

2.2- Sorbate: Contaminated liquid was collected from the radiochemistry laboratories in $\mathrm{Al}$ Tuwaytha site. The sorbate liquid used in this work is Cs-137.

\section{3- Equipment}

The qualitative analysis of radionuclides was performed via gamma spectrometry analysis using high-purity germanium detector (HPGe) with $65 \%$ relative efficiency, $1.95 \mathrm{keV}$ energy resolution, and $1.33 \mathrm{MeV}$ of ${ }^{60} \mathrm{Co}$ isotope. Roller mixer was used to mix the sorbent and sorbate materials. Sensitive balance (Denver instrument - made in Germany) was utilized to measure weight of samples.

2.4- Adsorption isotherm: The batch process was applied to find the adsorption of cesium- 137 ions upon bentonite. Five samples with different activity concentrations were used to study sorption isotherm. The isotherm models used in the present work were the Langmuir and Freundlich models.

The amount of substance adsorbed at equilibrium is [10]:

$$
\mathrm{q}_{\mathrm{e}}=\left(\mathrm{C}_{\circ}-\mathrm{C}_{\mathrm{e}}\right) \mathrm{V} / \mathrm{W}
$$

where $\mathrm{C}_{\mathrm{o}}$ is the initial concentration, $\mathrm{C}_{\mathrm{e}}$ is the concentration at equilibrium, $\mathrm{V}$ is the volume of fluid, and $\mathrm{W}$ is the weight of the adsorbent.

The removal efficiency is calculated as follows $[10,11]$ :

$$
\text { Removal efficiency } \%=\left(\frac{C_{\circ}-C_{e}}{C_{\circ}}\right) \times 100 \%
$$

The Langmuir isotherm equation is represented as follows [12]:

$$
\frac{\mathrm{C}_{\mathrm{e}}}{\mathrm{q}_{\mathrm{e}}}=\frac{1}{\mathrm{q}_{\mathrm{m}} \mathrm{b}}+\frac{1}{\mathrm{q}_{\mathrm{m}}} \mathrm{C}_{\mathrm{e}}
$$

where $\mathrm{q}_{\mathrm{m}}$ and $\mathrm{b}$ are Langmuir constants and they can be calculated by plotting $\mathrm{C}_{\mathrm{e}} / \mathrm{q}_{\mathrm{e}}$ against $\mathrm{C}_{\mathrm{e}}$. The Freundlich equation is represented as follows [13]:

$$
\log \left(\mathrm{q}_{\mathrm{e}}\right)=\frac{1}{n} \log \left(\mathrm{C}_{\mathrm{e}}\right)+\log \left(\mathrm{K}_{\mathrm{f}}\right)
$$
$\left(\mathrm{C}_{\mathrm{e}}\right)$.

where $\left(\mathrm{K}_{\mathrm{f}}\right.$ and $1 / \mathrm{n}$ are Freundlich constants and can be found via plotting $\log \left(\mathrm{q}_{\mathrm{e}}\right)$ against $\log$

\section{3- Results and discussion}

The plot of activity versus mixing time, with a weight of $0.01 \mathrm{~g}$ and $\mathrm{pH}=6.8$, is shown in Figure-2, where the activity decreases with increasing mixing time. In addition, the greatest removal of cesium ions was recorded during the first half hour, while the equilibrium time was 2 hours. 




Figure 2-Effects of mixing time on the activity.

The plot of activity versus weight, with a constant time of $2 \mathrm{~h}$ and $\mathrm{pH}=6.8$, is shown in Figure-3. The activity was decreasing with the increase in the weight of sorbent material, while the greatest removal efficiency was found at a weight of $0.04 \mathrm{~g}$.

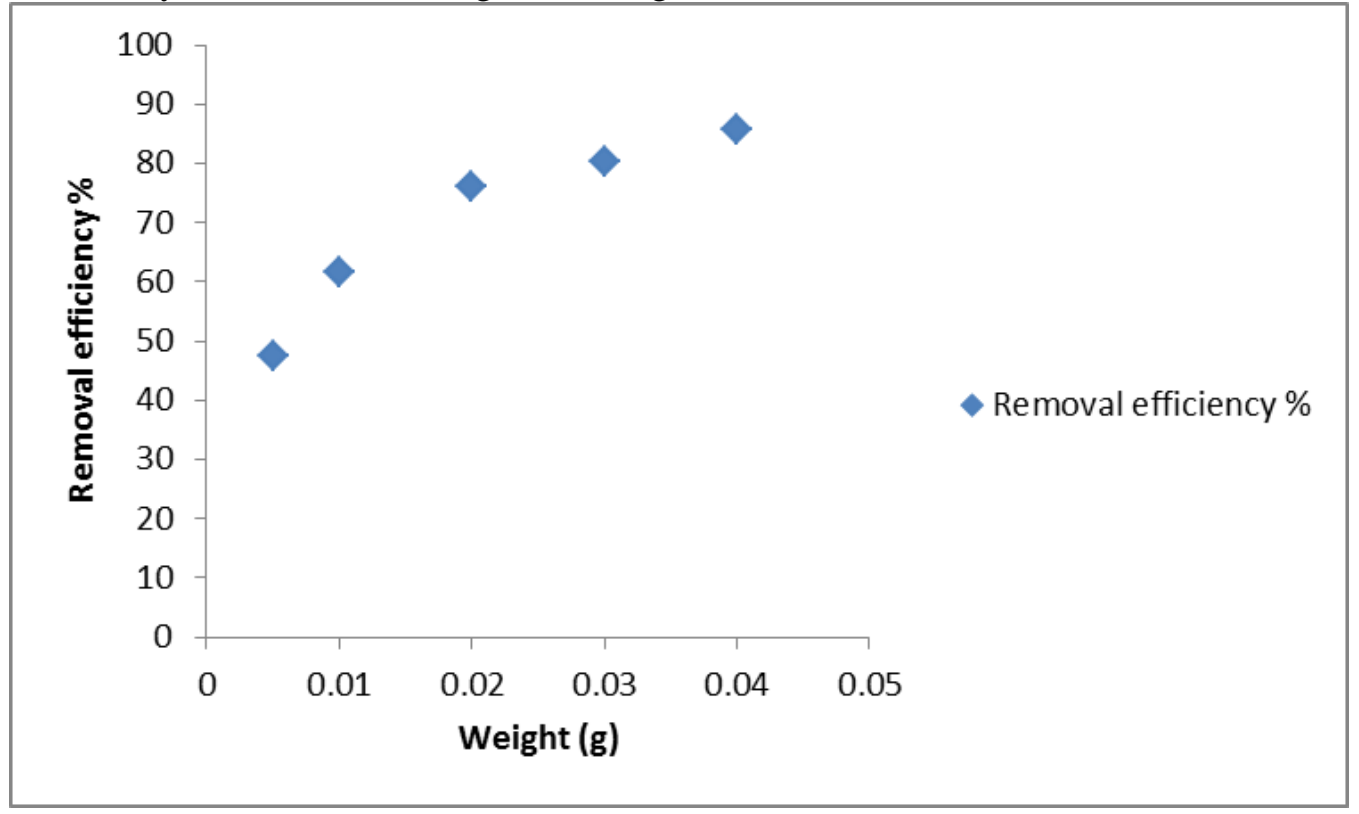

Figure. 3-Effects of weight on the activity.

Figure- 4 shows the increasing removal efficiency with increasing $\mathrm{pH}$. At low $\mathrm{pH}$, surplus $\mathrm{H}^{+}$which is present in the fluid competes with the studied element ions for active locations, leading to less removal of element ions and negatively-charged surface hydroxyl groups. Therefore, the removal efficiency will decrease. 


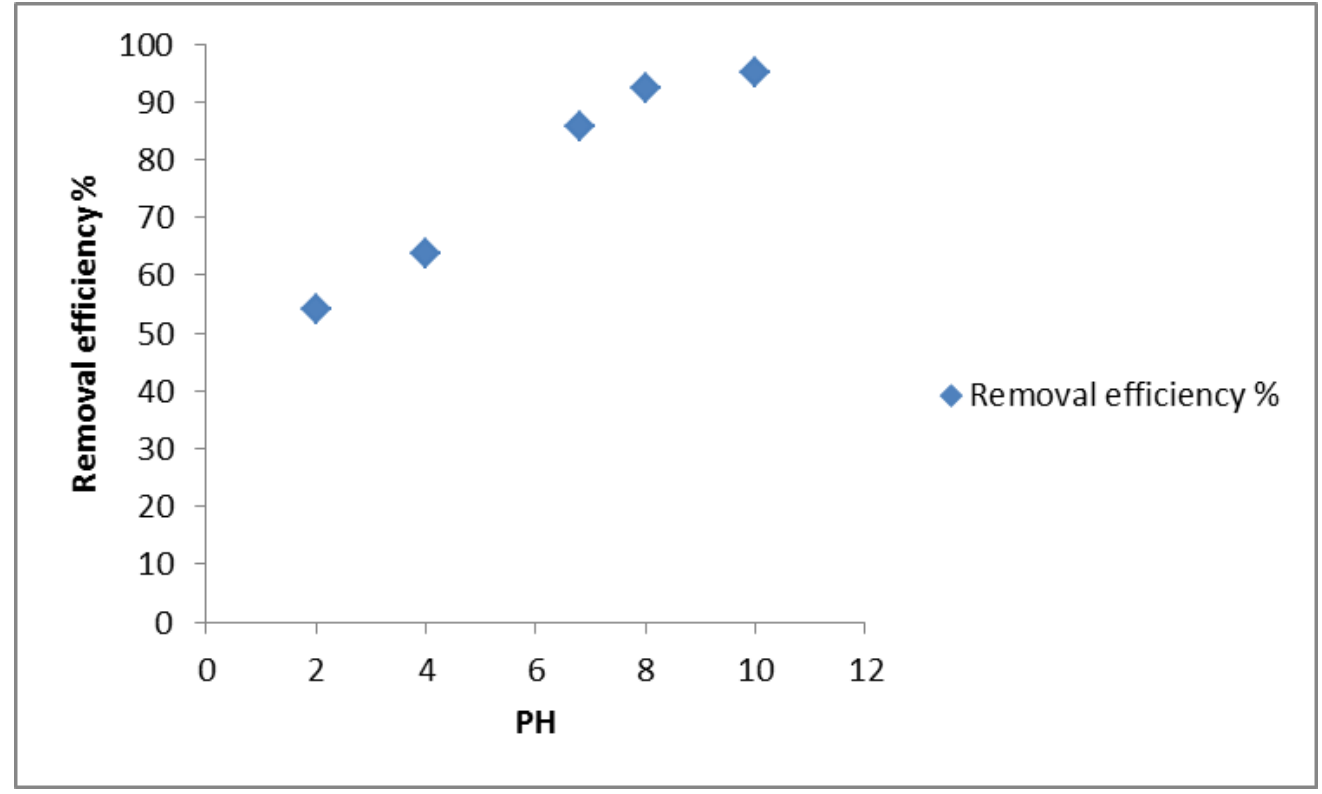

Figure 4-Effects of $\mathrm{pH}$ on removal efficiency.

The plot of removal efficiency (\%) versus initial concentration, with time of $2 \mathrm{~h}, \mathrm{pH}=6.8$, and weight of $0.04 \mathrm{~g}$, is shown in Figure-5. The removal efficiency was increased with increasing the initial concentration.

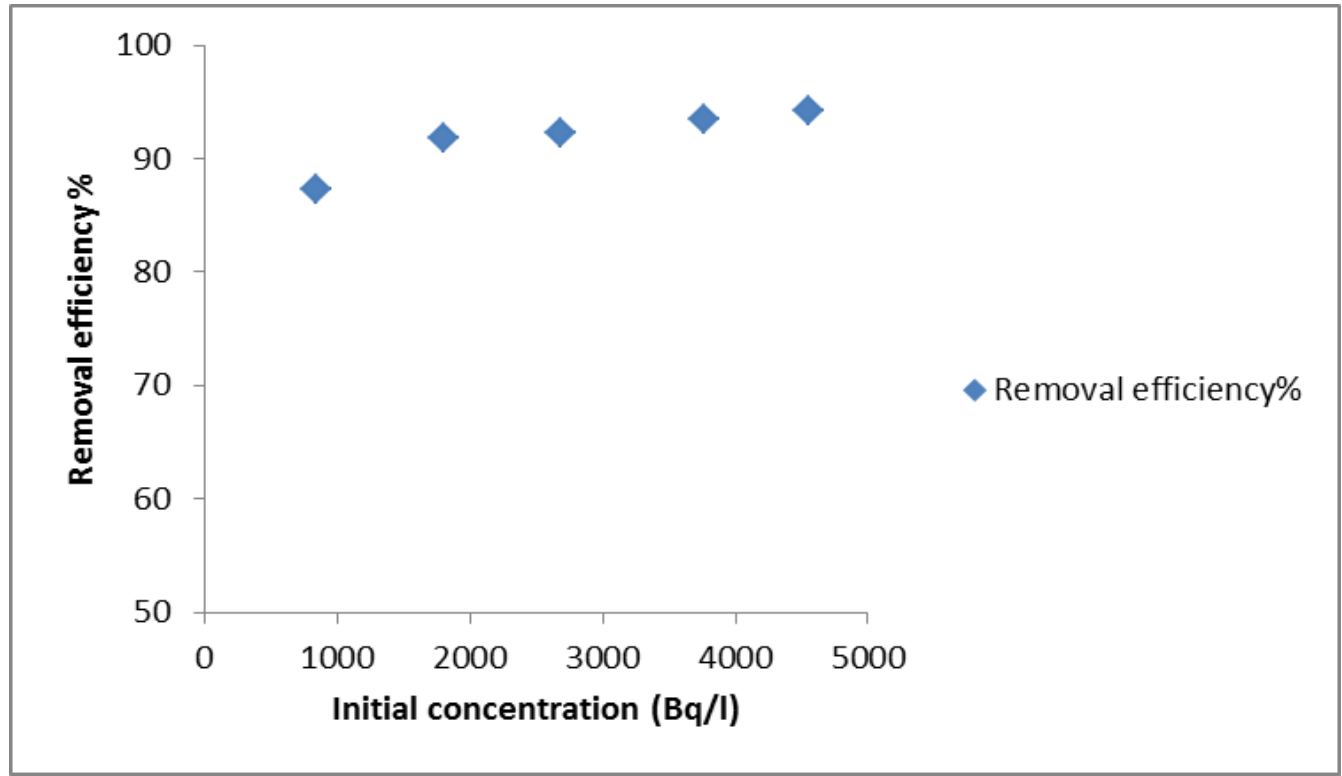

Figure 5-Effects of initial concentration on removal efficiency.

\section{1- Equilibrium isotherms}

Figure-6 shows the linear relationship of the isotherm Langmuir model, which includes the relationship between the equilibrium concentration and the amount of adsorbed material at equilibrium (Ce /qe against $\mathrm{Ce}$ ). 


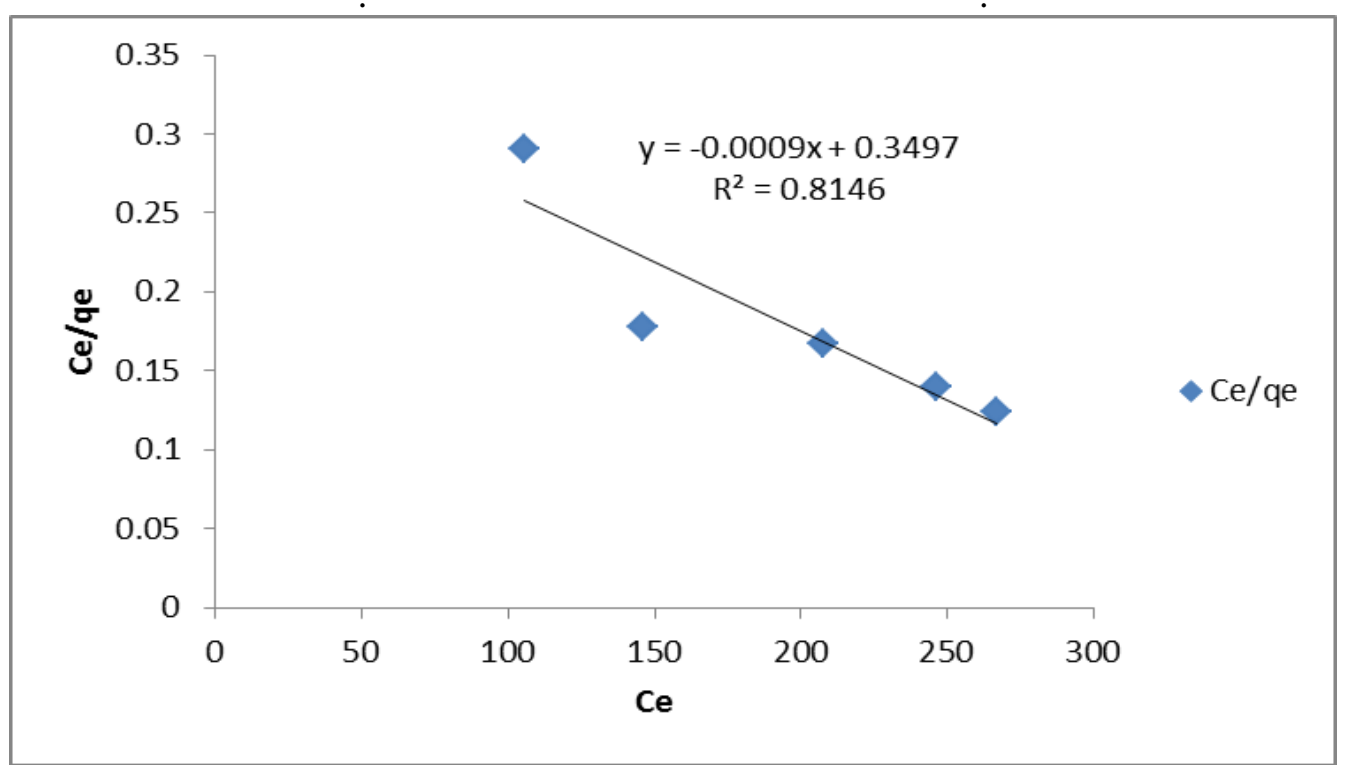

Figure 6-Langmuir plot of $\mathrm{C}_{\mathrm{e}} / \mathrm{q}_{\mathrm{e}}$ against $\mathrm{C}_{\mathrm{e}}$ for the adsorption of cesium-137 on bentonite.

Figure-7 shows the linear relationship of the isotherm Freundlich model, which includes the relationship between $\log$ qe and $\log$ Ce.

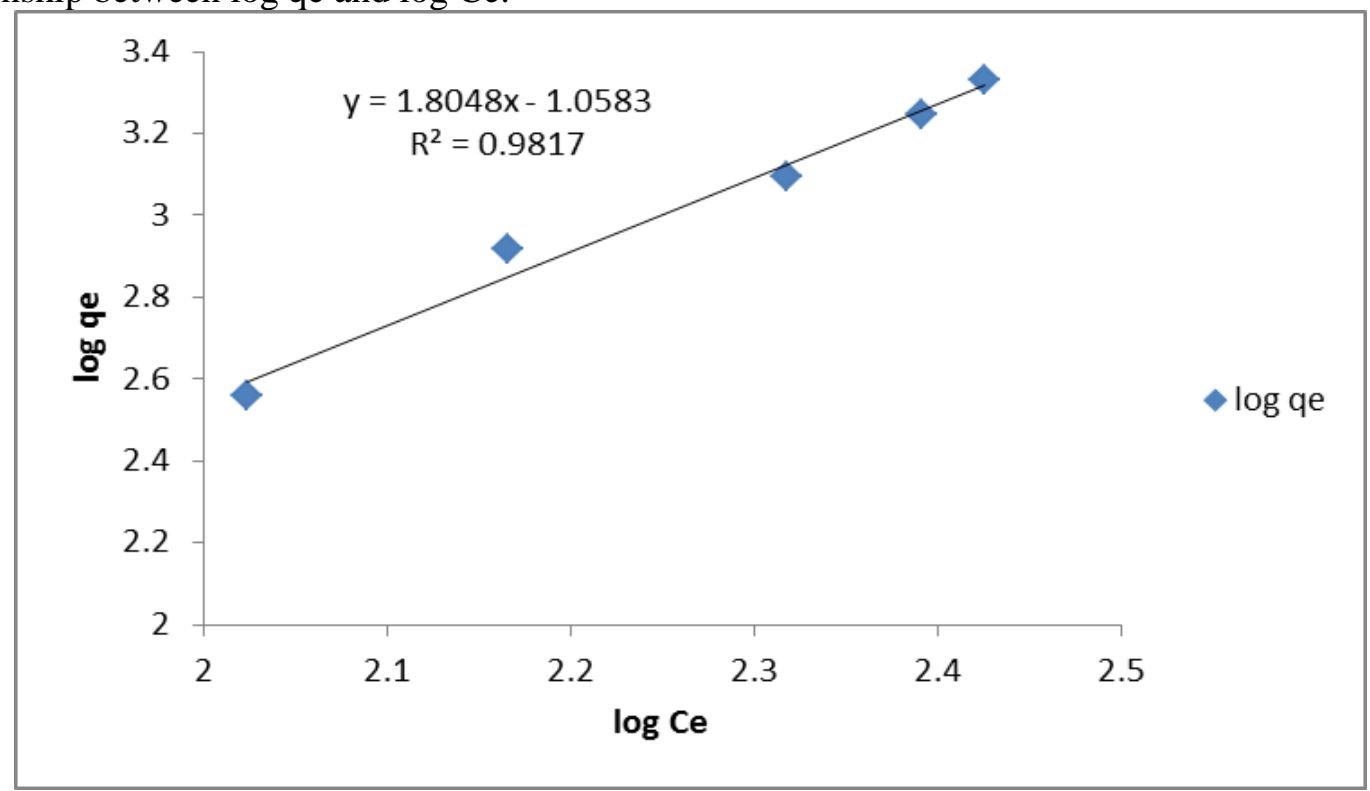

Figure 7-Freundlich plot of $\log \mathrm{q}_{\mathrm{e}} \mathrm{vs} . \log \mathrm{C}_{\mathrm{e}}$ for the adsorption of cesium-137 on bentonite.

The constants of Langmuir and Freundlich models with their correlation coefficients are listed in Table-2.

Table 2-Equilibrium isotherm model constants and correlation coefficients.

\begin{tabular}{|c|c|c|c|c|c|}
\hline \multirow{2}{*}{$\begin{array}{c}\text { Isotherm } \\
\text { model }\end{array}$} & $\mathbf{q}_{\mathbf{m}}$ & $\mathbf{b}$ & $\mathbf{n}$ & $\mathbf{K}_{\mathbf{f}}$ & $\begin{array}{c}\text { Linear } \\
\text { correlation } \\
\text { coefficient }\left(\mathbf{R}^{2}\right)\end{array}$ \\
\hline Langmuir & -1111.11 & -0.0025736 & & & 0.8146 \\
\hline Freundlich & & & 0.554078 & 0.347045 & 0.9817 \\
\hline
\end{tabular}

The values of linear correlation coefficients $\left(\mathrm{R}^{2}\right)$ were 0.8146 and 0.9817 for Langmuir and Freundlich isotherm models, respectively. Freundlich model had a higher correlation coefficient than that of the Langmuir model. This implies that Freundlich model better fits the experimental results than Langmuir model. 


\section{4- Conclusions}

According to the results, the present study could reach a number of conclusions:

- $\quad$ The equilibrium time was $2 \mathrm{~h}$.

- The best weight of sorbent material to remove radioactive cesium was $0.04 \mathrm{~g}$.

- The removal efficiency was directly proportional to the $\mathrm{pH}$ value, since the greatest removal efficiency was at $\mathrm{pH}=10$, while the smallest removal efficiency was at $\mathrm{pH}=2$.

- The removal efficiency was directly proportional to the initial concentrations.

- Linear correlation coefficient $\left(\mathrm{R}^{2}\right)$ values for Freundlich and Langmuir models were 0.9817 and 0.8146, respectively. Both models presented good experimental results, but Freundlich model was best suited to these results.

\section{5- References}

1. Rasmey, A. M., Aboseidah, A. A. and Youssef, A. K. 2018. Application of Langmuir and Freundlich isotherm models on biosorption of $\mathrm{Pb} 2+$ by freez-dried biomass of pseudomonas aeruginosa. Egyptian journal microbiology, 53: 37- 48.

2. Sulaymon A. H., Afaj A. H. and Rasheed H. M. 2013. Treatment of Radioactive Liquid Waste using Iraqi Geological Raw Materials and Zeolite. Nahrain University, College of Engineering Journal (NUCEJ), 16(1): 58 - 66.

3. Shahwan T. and Erten H.N. 2002. Thermodynamic Parameters of $\mathrm{Cs}^{+}$Sorption on Natural Clays. J. Radio and Nucl. Chem., 253: 115-120.

4. Ebner A.D., Ritter J.A. and Nauratil J.D. 2001. Adsorption of Cesium, Strontium, and Cobalt Ions on Magnetite and a Magnetite-Silica Composite. Ind. Eng. Chem. Res., 40: 1615-1623.

5. Afaj A. H., Aziz Y.A. and Zaiter M.J. 2007. Treatment of Low and Intermediate Level Radioactive Liquid Waste from Al-Tiwatha Site using Iraqi Zeolite. Journal of Engineering, 13(1): 1237-1250.

6. IAEA-TECDOC-1336.2003. Combined Methods for Liquid Radioactive Waste Treatment, Vienna.

7. Yu B., Chem J. and Zhu X.W. 2002. Research Progress of Cesium-137 Removal Acidic HighLevel Liquid Waste. Nucl. Sci. Technol. 12(1): 51-57.

8. Adabbo M., Caputo D. and Gennaro B.D. 1999. Ion Exchange Selectivity of Philip Site of Cs and Sr as a Function of a Framework Composition. Micropor. Mesopor. Mat. 28(2): 315-324.

9. Muhammad N. P. J., Smith M. D. and Whealtey A. D. 1998. Adsorption of Heavy Metals in Slow Sand Filters . Proceedings of the 24th WEDC International Conference on Water Treatment, Islamabad, Pakistan, 346-349.

10. Kumar K. V., subanandam K., Ramamurthi V. and Sivanesan S. 2005. Solid Liquid Adsorption for Wastewater Treatment: Principle Design and Operation. College Technology, Anna University, Chennai-India, 41(5):1198-1202.

11. Jorfi, S., Ahmadi, M.J., Pourfadakari, S., Jaafarzadeh, N., Soltani, R.D.C. and Akbari, H. 2017. Adsorption of $\mathrm{Cr}$ (VI) by natural clinoptilolite zeolite from aqueous solutions: isotherms and kinetics. Polish journal of chemical technology, 19(3): 106-114.

12. Ho Y. S. 2003. Removal of Copper Ions from Aqueous Solution by Tree Fern . Wat. Res., 37: 2323-2330.

13. Ho Y. S., Porter J. F. and McKay G. 2002. Equilibrium Isotherm Studies for the Sorption of Divalent Metal Ions onto Peat: Copper, Nickel and Lead single Component Systems. Water, Air and Soil Pollution, 141: 1-33. 